Article

\title{
Accelerated Charge Dissipation by Gas-Phase Fluorination on Nomex Paper
}

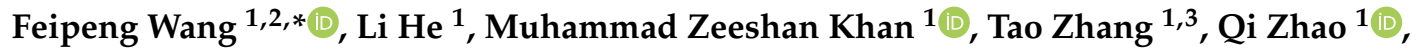 \\ Yushuang $\mathrm{He}^{1}$, Zhengyong Huang ${ }^{1}$, Haisen Zhao ${ }^{4}$ and Jian Li ${ }^{1}$ \\ 1 State Key Laboratory of Power Transmission Equipment \& System Security and New Technology, \\ Chongqing University, Chongqing 400044, China \\ 2 Shanghai Key Laboratory of Special Artificial Microstructure Materials and Technology, \\ Shanghai 200082, China \\ 3 CISDI Information Technology CO., LTD., Chongqing 400013, China \\ 4 Jinzhong Power Supply Company of State Grid Shanxi Electric Power Company, Shanxi 030001, China \\ * Correspondence: fpwang@cqu.edu.cn; Tel.: +86-1858-076-8887
}

Received: 22 August 2019; Accepted: 10 September 2019; Published: 16 September 2019

check for updates

\begin{abstract}
The surface charge and space charge accumulation in paper used in oil-paper insulation system may distort electric field distribution and lead to the flashover and breakdown of insulation system. In this paper, the effect of gas-phase fluorination on the surface charge and space charge characteristics of oil-impregnated Nomex paper was investigated. Nomex T410 was fluorinated at $25^{\circ} \mathrm{C}$ using $\mathrm{F}_{2} / \mathrm{N}_{2}$ mixtures with $20 \% \mathrm{~F}_{2}$ in volume at $0.05 \mathrm{MPa}$ for 15,30 and $45 \mathrm{~min}$. Fourier Transform Infrared Spectroscopy (FTIR) proved that the molecular chain scission and cleavage occurred during gas-phase fluorination. Furthermore, the surface charge and space charge characteristic of the original and fluorinated oil-impregnated paper were measured using an electrostatic voltmeter and Pulsed Electroacoustic (PEA) equipment respectively. Furthermore, the hole and electron trap distribution of the samples were obtained by Isothermal Surface Potential Decay (ISPD) model. The results showed that both the positive and negative charge decay rates were accelerated by gas-phase fluorination and the hole, electron trap energy and density of the fluorinated samples were reduced by fluorination. It is suggested that the space charge dissipation was also accelerated by fluorination, indicating that gas-phase fluorination is an effective approach to modify the charge dynamics of oil-impregnated Nomex paper.
\end{abstract}

Keywords: Nomex paper; gas-phase fluorination; surface charge; space charge; trap distribution

\section{Introduction}

Nomex paper has been recognized as an excellent insulation material due to its good thermal stability, stable mechanical and electrical properties and has been widely used in dry-type, converter and oil immersed transformers among others, in which the reliability of the oil-paper insulation system greatly influences the safety of the power transmission system [1,2]. Previous researches indicate that the surface charge accumulated on the oil paper interface and the space charge accumulated in the oil impregnated paper may accelerate the degradation process of the oil paper insulation system, distort the electric field distribution and lead to insulation failures such as flashover and breakdown $[3,4]$. Therefore, a series of studies on the charge dynamic of the oil paper insulating system has been carried out and various approaches have been conducted to modify surface charge and space charge characteristics of the oil paper insulation system.

In recent years, various influence factors on the charge dynamics of the oil paper insulation system have been studied. Tang et al. [5] investigate the space charge characteristic of multi-layer oil-paper 
insulation under different DC voltages and temperatures using the PEA technique; Hao et al. [6] measured the space charge distribution in multilayer oil-paper insulation with different moisture content; $\mathrm{Wu}$ et al. [7] proposed a waveform recovery method to obtain accurate charge distribution in the oil-immersed-paper/oil insulations. Wang et al. [8] and Huang et al. [9] studied the influence of thermal aging and voltage reversal on the space charge characteristic of oil-impregnated paper insulation, respectively. Moreover, Du et al. $[4,10]$ investigated the surface charge accumulation and dissipation of oil impregnated paper under DC and pulse voltage.

However, the increasing voltage level of a power transmission system calls for higher reliability of insulation materials. It is necessary to research and develop materials used in oil paper insulation with better electrical, mechanical, and thermal properties. Therefore, many approaches have been used to modify the performance of the insulation oil and the paper. Nanoparticles such as $\mathrm{C}_{60}, \mathrm{Fe}_{3} \mathrm{O}_{4}, \mathrm{BN}$ and $\mathrm{TiO}_{2}$ [11-13] have been used to improve the dielectric strength of insulation oil. Recently, CdS and graphene quantum dots have also been added in the insulation oil to improve its breakdown voltage and thermal conductivity [14,15]. Furthermore, Tang et al. [16] and Liao et al. [17] have synthesized nanoparticles modified insulation paper and investigated the influence of doped nanoparticles on the thermal and electrical properties of cellulose insulation paper.

Surface modification is considered to be an effective method to improve the surface performance of materials without deteriorating the properties of matrix. For example, various kind of plasma treatments of cellulose paper have been utilized to enhance their hydrophobicity [18-20]. As one of the most commonly used surface modification method, gas-phase fluorination has already been used to modify the surface charge and space charge dynamics of polymer such as polyethylene, polypropylene, polyimide and epoxy resin [21-24]. Previous studies also show that the surface charge dissipation of oil-impregnated cellulose insulation paper under DC and pulse voltage could be accelerated by gas-phase fluorination [25]. Nomex paper is one kind of insulation paper with better performance compared with cellulose insulation paper. The high resistivity of Nomex paper would result in the slower decay rate of the accumulated charge, therefore it is necessary to find a proper method to modify the charge dynamics of Nomex paper.

In this paper, an attempt was made to modify the surface properties of Nomex paper by gas-phase fluorination. The surface chemical structure, surface charge and space charge dynamics of oil-impregnated Nomex paper before and after fluorination were investigated. The results showed that gas-phase fluorination could accelerate the surface charge and space charge dissipation of oil-impregnated Nomex paper.

\section{Experimental Section}

\subsection{Sample Preparation}

DuPont T410 Nomex paper with diameter of $5 \mathrm{~cm}$ and thickness of $130 \mu \mathrm{m}$ was dried in vacuum at $60^{\circ} \mathrm{C}$ for $24 \mathrm{~h}$ before fluorination. Gas-phase fluorination was performed in stainless steel chamber. Before fluorination, nitrogen $(99.999 \%)$ was utilized to evacuate and purify the reaction vessel for five times, then $\mathrm{F}_{2} / \mathrm{N}_{2}$ mixtures with $20 \% \mathrm{~F}_{2}$ in volume at $0.05 \mathrm{MPa}$ was introduced into the reaction vessel. The paper was fluorinated for a duration of 15, 30 and 45 min (marked as F15, F30 and F45 respectively, while the original sample was marked as F0), the reaction vessel was purged again with nitrogen for five times after treatment. To prepare the oil-impregnated paper, the original and fluorinated samples were dried in vacuum chamber at $40{ }^{\circ} \mathrm{C}$ for $48 \mathrm{~h}$ to further purify the moisture, and the samples were impregnated into Karamay $25 \#$ mineral oil and kept in vacuum at $40{ }^{\circ} \mathrm{C}$ for $24 \mathrm{~h}$. Then the filtration of the oil-impregnated paper was performed for $5 \mathrm{~s}$ using a sand core funnel to clean the oil residue on samples surface. 


\subsection{Sample Characterization}

Attenuated Total Reflection Fourier Transform Infrared Spectroscopy (ATR-FTIR) was utilized to characterize the surface chemical bonding variation before and after fluorination (Bruker Alpha). Isothermal surface potential decay was performed using the setup shown in Figure 1, which was mainly structured by a needle-grid-plate electrode and a kelvin probe operated by an electrostatic voltmeter. A tungsten needle with radius of curvature of $50 \mu \mathrm{m}$ was placed $5 \mathrm{~mm}$ above the sample surface. For corona charging, $\pm 8 \mathrm{kV}$ and $\pm 5 \mathrm{kV}$ DC voltage were applied to the needle and grid electrode respectively for $10 \mathrm{~min}$. The surface potential was measured immediately after charging (within $5 \mathrm{~s}$ ) by a kelvin probe ( $3 \mathrm{~mm}$ above sample). All experiments were performed at room temperature of ca. $25^{\circ} \mathrm{C}$ and $\mathrm{RH} \sim 30 \%$. To further understand the influence of gas-phase fluorination on charge dynamics of oil-impregnated Nomex paper, the PEA system was utilized to carry out the space charge measurement [26]. AVIR-1-C pulse module produced by AVTECH company could provide pulse voltage with an amplitude up to $200 \mathrm{~V}$ and pulse width $2 \sim 5 \mathrm{~ns}$. AU-20R3-LC high voltage DC source produced by MATSUSADA company could provide the applied voltage up to $\pm 20 \mathrm{kV}$ and the acoustic coupling agent was silicone oil. The space charge accumulation and dissipation under DC stress of $-15 \mathrm{kV} / \mathrm{mm}$ were obtained at ambient temperature $(25 \pm 1)^{\circ} \mathrm{C}$, relative humidity $(50 \pm 2) \%$. The space charge distribution at different application time $(5 \mathrm{~s}, 10 \mathrm{~s}, 60 \mathrm{~s}, 300 \mathrm{~s}$ and $900 \mathrm{~s})$ and different voltage off time $(5 \mathrm{~s}, 10 \mathrm{~s}, 60 \mathrm{~s}, 300 \mathrm{~s}$ and $600 \mathrm{~s})$ were extracted in this paper.

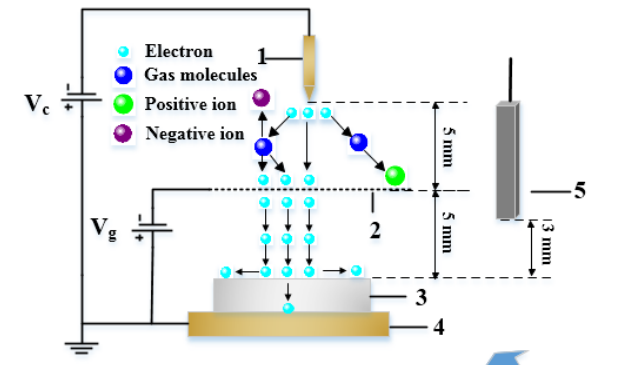

\section{Needle Electrode}

2. Mesh Grid

3. Sample

4. Back ground electrode

5. Kelvin probe

6. Motorized Linear Stages

7. Data acquisition system

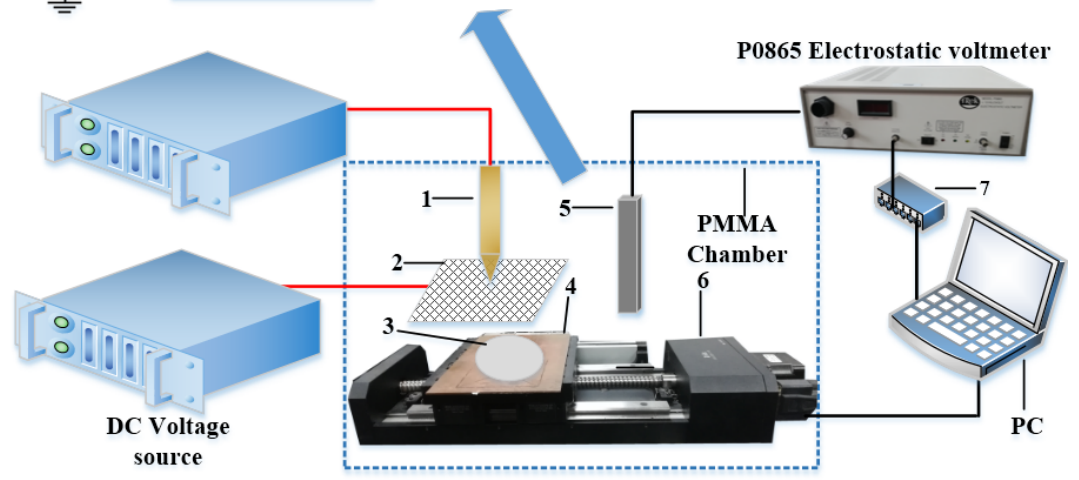

Figure 1. Schematic illustration of the isothermal surface potential decay measurement.

\section{Results and Discussion}

\subsection{Surface Chemical Structure}

The molecule chain of Nomex paper, which mainly consists of wholly-rigid aromatic polyamide poly (m-phenylene isophthalamide) (PMIA), is shown in Figure 2. Figure 3 shows ATR-IR spectrum of Nomex paper before and after fluorination. As shown in Figure 3, the absorption peak located at $3280 \mathrm{~cm}^{-1}$ in the original sample represents the N-H stretching vibration of amide. Similarly, absorption peaks located at 1644, 1600, 1532 and $1233 \mathrm{~cm}^{-1}$ represent the $\mathrm{C}=\mathrm{O}$ stretching vibration of amide, $\mathrm{C}=\mathrm{C}$ stretching vibration of benzene, $\mathrm{C}-\mathrm{N}-\mathrm{H}$ stretching vibration of amide and the $\mathrm{C}-\mathrm{N}$ stretching vibration of amide, respectively [27]. Moreover, a conspicuous absorption peak of C-F, $\mathrm{C}-\mathrm{F}_{2}$ and $\mathrm{C}-\mathrm{F}_{3}$ bond emerges between wavenumbers of $900 \mathrm{~cm}^{-1}$ and $1300 \mathrm{~cm}^{-1}$ in the fluorinated 
samples and the intensity increases with the extension of fluorination duration [25]. In addition, a new absorption peak corresponding to the aliphatic aldehydes (R-CHO) groups appears at $1725 \mathrm{~cm}^{-1}$ in the fluorinated samples, as can be seen in Figure 3. Due to high oxidation of fluorine gas, element substitution, chain scission and cross-linking reaction occurred simultaneously and thus modified the surface properties of the polymer. It is obvious that the absorption peaks located at 3280, 1644, 1600,1532 and $1233 \mathrm{~cm}^{-1}$ are reduced after fluorination, indicating that $\mathrm{H}$ element was substituted by $\mathrm{F}$ element during fluorination and meanwhile, the fracture of $\mathrm{C}=\mathrm{O}, \mathrm{C}=\mathrm{C}, \mathrm{C}-\mathrm{N}-\mathrm{H}$ and $\mathrm{C}-\mathrm{N}$ bonds occurred during fluorination. In addition, the formation of $\mathrm{R}-\mathrm{CHO}$ proves that gas-phase fluorination would lead to the benzene ring opening.

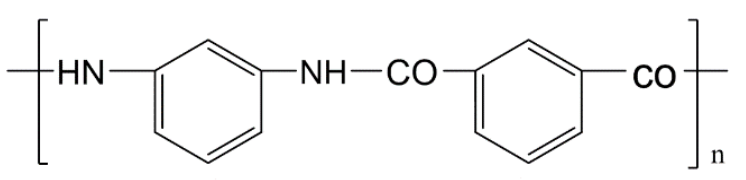

Figure 2. Structure of PMIA (Nomex) molecule chain.

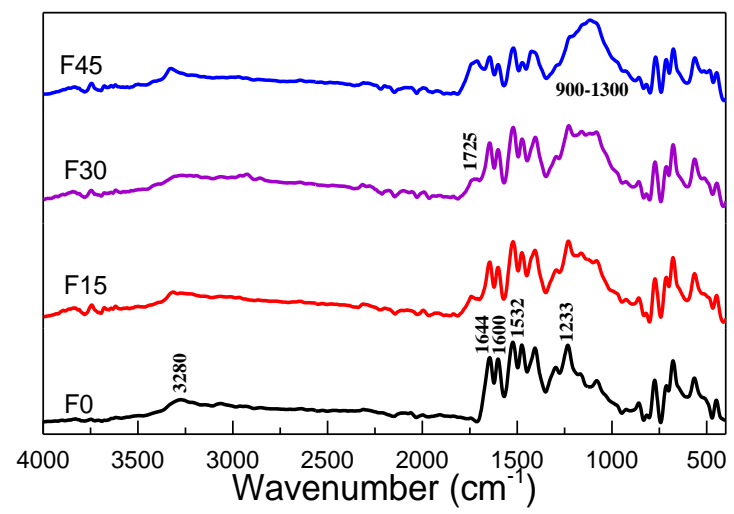

Figure 3. ATR-FTIR spectrums of Nomex paper before and after fluorination.

\subsection{Surface Charge Accumulation and Dissipation}

Isothermal surface potential decay (ISPD) model was utilized to characterize the trap energy and distribution of the samples. Based on the ISPD model, the trap energy level $E_{t}$ and trap density $N\left(E_{t}\right)$ can be calculated as [28],

$$
\begin{gathered}
E_{t}=k T \ln (v t) \\
N\left(E_{t}\right)=\frac{\varepsilon_{0} \varepsilon_{r} t}{k T \delta L q} \frac{d V_{S}}{d t}
\end{gathered}
$$

where $k$ is the Boltzmann constant, $T$ is the absolute temperature, $v$ equaling to $4.17 \times 10^{13}, s$ is the attempt to escape frequency of the trapped electron, $\varepsilon_{0}$ and $\varepsilon_{r}$ are the vacuum permittivity and relative permittivity of dielectric, $q$ is the Coulomb's quantity of electrons, $\delta=2 \mu \mathrm{m}$ is the thickness of the top charge layer, and $L$ is the sample thickness.

Figure 4 presents the positive and negative surface potential decay curve of sample F0, F15, F30 and F45 after implementation of $\pm 5 \mathrm{kV}$ DC (grid electrode) for $10 \mathrm{~min}$. The initial potential and $t_{50}$, the time when the surface potential decays to $50 \%$ of the initial potential, are also utilized to characterize the surface charge characteristic. It can be seen that both the positive and negative surface potential decay rate decreased with the extension of time; moreover, the decay rate increased when the fluorination duration was prolonged from 0 to $30 \mathrm{~min}$ and decreased when the duration was further prolonged from 30 to $45 \mathrm{~min}$. During the corona charging, the carriers including electron, positive and negative ions would deposit on sample surface and would be captured by surface trap, followed by the thermal de-trapping just after the charging voltage was off. Since, the de-trapped time was shorter in shallow 
trap [4], the charges trapped in the shallow trap were more likely to dissipate in the initial stage during surface potential decay, and then the de-trapping of charges trapped in the deep trap would result in the deceleration of surface potential decay. Both the positive and negative surface potential decay rate of all the fluorinated samples were faster than the original samples, indicating that gas-phase fluorination had excellent suppression effect of surface charge accumulation in oil-impregnated Nomex paper.

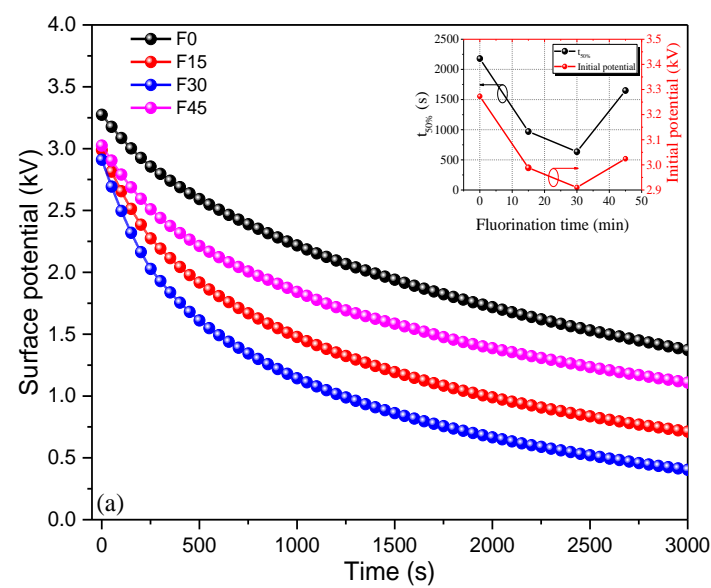

(a)

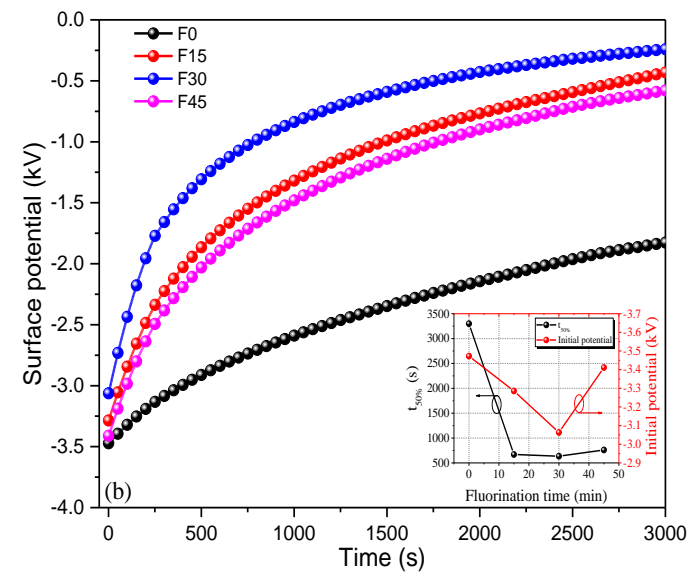

(b)

Figure 4. Surface potential decay of oil-impregnated Nomex paper with different fluorination duration:

(a) Positive charging; (b) negative charging for $10 \mathrm{~min}$.

To further understand the influence of gas-phase fluorination on the surface potential decay and surface trap characteristics of oil-impregnated Nomex paper, the hole and electron trap distribution with different fluorination duration were obtained by isothermal surface potential decay method, and the trap density and energy level of shallow and deep trap are fitted with double exponential functions based on the double trap model [28]. The obtained hole and electron trap distribution of F0, F15, F30 and F45 samples are shown in Figures 5 and 6, respectively.

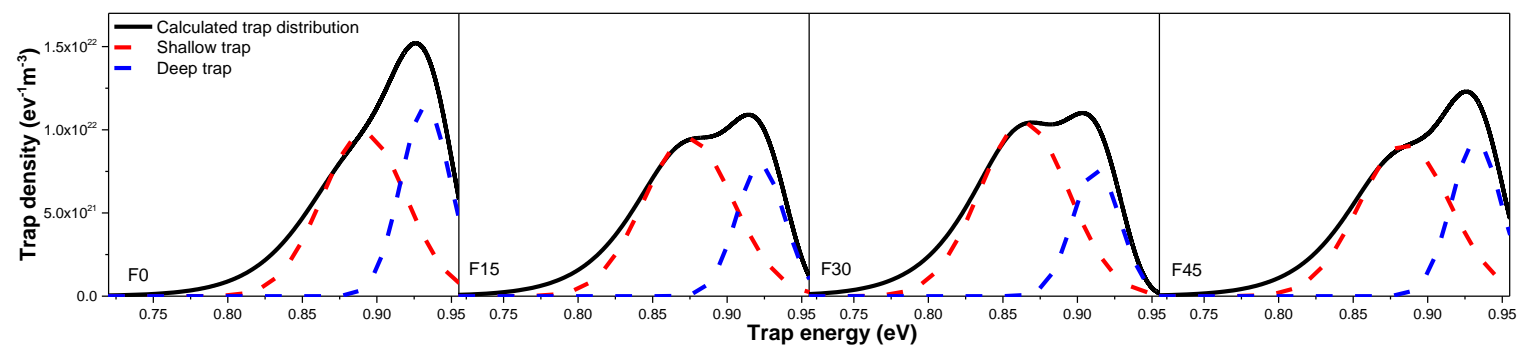

Figure 5. Relationship between fluorination duration and hole trap distribution of oil-impregnated Nomex paper.

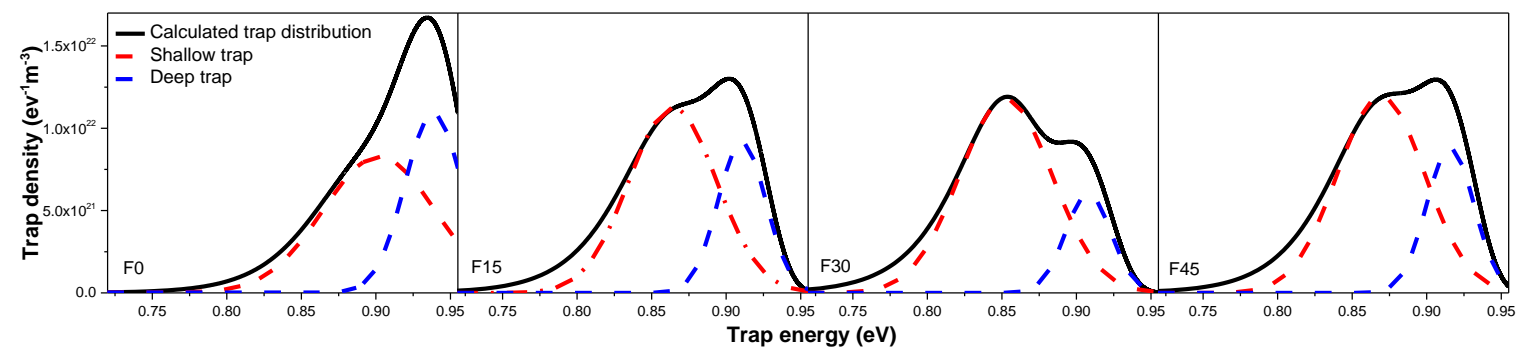

Figure 6. Relationship between fluorination duration and electron trap distribution of oil-impregnated Nomex paper. 
It can be observed in Figures 5 and 6 that all of the trap moved toward to a lower energy band after fluorination. The shallow trap density and energy level showed a similar change in both electron and hole trap with fluorination duration extended: The shallow trap energy level decreased and trap density increased when the fluorination duration was prolonged from 0 to $30 \mathrm{~min}$, and then developed in the opposite tendency when the fluorination duration was prolonged to $45 \mathrm{~min}$. Meanwhile, both the energy level and the deep trap density decreased first and then increased, and reached the minimum at F30. As we know, the de-trapping probability of charge carriers can be calculated as follows [29]:

$$
P_{d e}=v e^{-\frac{E_{t}}{k T}}
$$

where $P_{d e}$ is the de-trapping probability of charge carriers, which means that the decrease of energy level $E_{t}$ will result in the promotion of de-trapping probability. Both the deep and shallow trap developed toward a lower energy level compared with original samples, thereby increasing the de-trapping probability of charge carriers, meaning the accumulated surface charges could easily dissipate and lead to a higher surface potential decay rate.

It can be seen from the ATR-IR results that an obvious molecular structure change occurred during fluorination and a large amount of molecular chain scission and cleavage would significantly influence the trap characteristic of the samples. The mechanism of physical and chemical defects can be used to explain the trap density and energy level variety of the samples before and after fluorination. With the extending of fluorination from 0 to $30 \mathrm{~min}$, the formation of physical defects were introduced by the structure change could be the main factor that leads to decrease in the deep trap, because the physical defects had much weaker bonding force than the chemical defects that were formed by introducing the highest electronegativity fluorine element [30]. When the continuous fluorination duration was extended to $45 \mathrm{~min}$, the increase of chemical defects may have resulted in the growing of the deep trap, because the fluorination reaction was very violent in the initial stage and tended to stabilize over time, which led to a steady development of the substitution reaction. The shallow trap was mainly influenced by the properties of the amorphous region. Since a large amount of the molecular chain was destroyed during fluorination, the crystallinity of the samples may have been reduced and the amorphous space increased, thus decreasing the trap energy level of the shallow trap. Moreover, it seems that gas-phase fluorination exerted a more significant influence on the electron trap than the hole trap, which may be attributed to the different main conduction approach of hole and electron. The hole valence band states have an intra-chain character as opposed to inter-chain for electron conduction [24], so the injected hole will be deeply trapped in the intra-chain defects along the chain backbone while the electron would be captured by the trap in the amorphous regions. Therefore, as the amorphous space expands, the effect of gas-phase fluorination on electron trap would become more pronounced.

\subsection{Space Charge Accumulation and Dissipation}

To investigate the influence of gas-phase fluorination on the space charge behavior of oil-impregnated Nomex paper, PEA was used to measure the space charge accumulation and dissipation of sample F0 and F30. Figure 7 shows the space charge distribution of sample F0 and F30 under different polarization times. Firstly, a large amount of space charge accumulated at the sample-electrode interface, i.e., positive charges accumulated near the anode (peak A) and negative charges accumulated near the cathode (peak B). With the increasing of polarization time, the positive charges accumulated near the anode gradually migrated to the matrix and positive charge peaks $C$ appeared in the middle of the sample. The peak charge volume increased with polarization time, which indicated that the induced positive charge migrated from the anode to the internal part. The positive charge peak in F30 was lower than that in F0 before $60 \mathrm{~s}$, indicating that fluorination could suppress the charge injection to some extent. A similar phenomenon could also be found in fluorinated LDEP [31]. From Figure 7a, it can be seen that for the non-fluorinated samples, the charge volume of peak B gradually increased 
and finally reached a stable value with the extension of polarization time, but the peak position still maintained in the sample-electrode interface. However, negative peak charge volume of sample F30 increased first and then decreased after the $60 \mathrm{~s}$ of polarization and the peak position tended to move inward in samples.

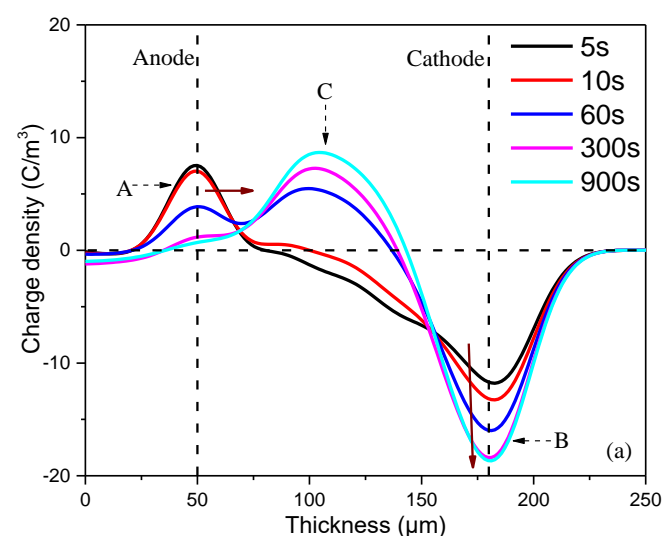

(a)

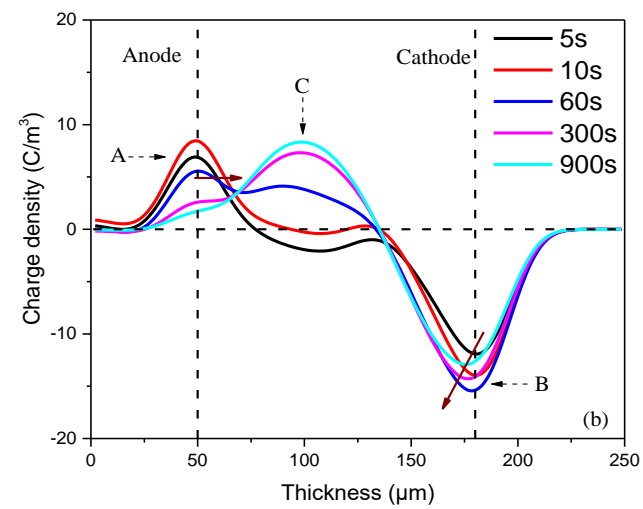

(b)

Figure 7. Space charge accumulation: (a) Original sample; (b) 30 min fluorinated sample.

Figure 8 presents the space charge distribution of sample F0 and F30 after voltage-off. It is observed that the density of negative charge near the cathode and the positive charge in middle of the sample decreased over time, meanwhile a negative peak appeared near the anode and then decreased to zero finally. By comparing the space charge decay rate of samples F0 and F30, it is evident that the fluorinated sample showed a better space charge suppression effect. From the trap energy and density distribution of the samples shown in Figures 5 and 6, it can be inferred that lower surface hole and electron deep trap density and trap energy level in the fluorinated sample were also beneficial for the space charge dissipation after the voltage off.

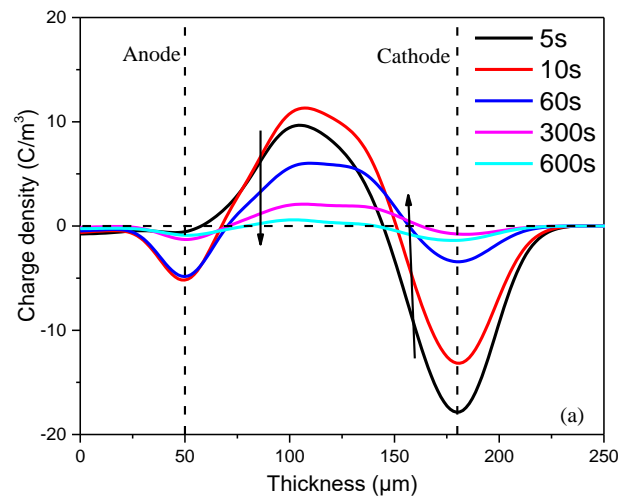

(a)

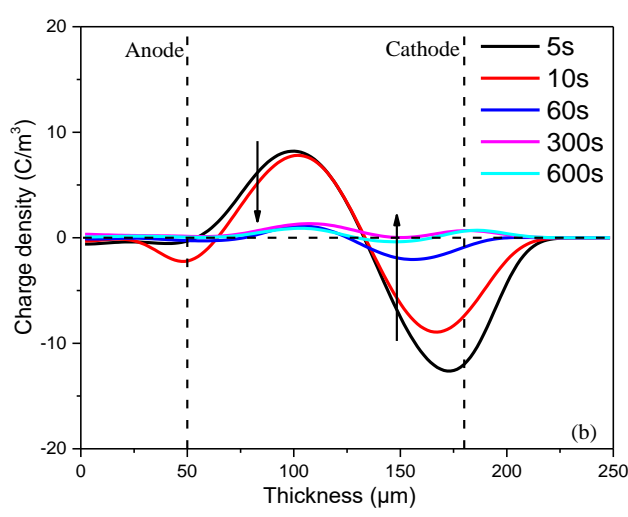

(b)

Figure 8. Space charge dissipation: (a) Original sample; (b) 30 min fluorinated sample.

\section{Conclusions}

In this paper, the influence of gas-phase fluorination on the surface charge and space charge characteristic of oil-impregnated Nomex paper were studied. The main conclusions are summarized as follows:

1. Gas-phase fluorination could be an effective approach to modify the surface charge dynamics of oil-impregnated Nomex paper. The considerable molecular chain scission and cleavage during fluorination are evident from ATR-IR spectra. The positive and negative surface potential decay 
rates are accelerated with the increase of fluorination duration and slowed down with continuous extension of fluorination duration. The samples fluorinated for $30 \mathrm{~min}$ show highest decay rate.

2. The trap energy level and density distribution obtained by the isothermal surface potential decay method show that gas-phase fluorination exerts a great influence on the trap characteristic of oil-impregnated Nomex paper, which is mainly attributed to the competition between physical and chemical defects change caused by fluorination. The difference between the hole trap and electron trap energy level and density of the original and the fluorinated samples are mainly caused by the different conduction path of hole and electron.

3. The space charge measured by the pulsed electro-acoustic (PEA) system shows that the charge mobility of the fluorinated samples is higher than that of the original sample. The negative charge of the fluorinated samples accumulated near the cathode shows obvious inward migration tendency, while the peak value is smaller compared to the non-fluorinated samples. The space charge decay rate of the fluorinated samples is also faster than the non-fluorinated one. Nevertheless, the influence of gas-phase fluorination on other electrical properties of oil-impregnated Nomex paper will be explored, because previous research has shown that gas-phase fluorination brings about remarkable improvement of flashover strength, partial discharge resistance or corona resistance of the polymer such as polyimide and epoxy resin.

Author Contributions: Conceptualization, L.H. and F.W.; methodology, T.Z. and L.H.; software, M.Z.K.; validation, Y.H.; formal analysis, L.H. and F.W.; investigation, Q.Z.; resources, J.L.; data curation, L.H.; writing-original draft preparation, L.H.; writing-review and editing, F.W.; visualization, M.Z.K.; supervision, J.L.; project administration, F.W.; funding acquisition, F.W., Z.H. and H.Z.

Funding: This research was funded by the National Key R\&D Program of China, grant number 2017YFB0903801, the Opening Project of Shanghai Key Laboratory of Special Artificial Microstructure Materials and Technology, grant number ammt2017A-3 and the Science and Technology Project of SGCC under Grant SGTYHT/14-JS-188.

Acknowledgments: The authors gratefully acknowledge supports from the National Key R\&D Program of China (2017YFB0903801), the Opening Project of Shanghai Key Laboratory of Special Artificial Microstructure Materials and Technology (ammt2017A-3) and the Science and Technology Project of SGCC (SGTYHT/14-JS-188).

Conflicts of Interest: The authors declare no conflict of interest.

\section{References}

1. Wen, M.; Song, J.; Song, Y.; Liu, Y.; Li, C.; Wang, P. Reliability assessment of insulation system for dry type transformers. IEEE Trans. Dielectr. Electr. Insul. 2013, 20, 1998-2008. [CrossRef]

2. Carrascal, I.A.; Fernández-Diego, C.; Casado, J.A.; Diego, S.; Fernández, I.; Ortiz, A. Quantification of Kraft paper ageing in mineral oil impregnated insulation systems through mechanical characterization. Cellulose 2018, 25, 3583-3594. [CrossRef]

3. Zhang, X.; Zahn, M.K. Kerr electro-optic field mapping study of the effect of charge injection on the impulse breakdown strength of transformer oil. Appl. Phys. Lett. 2013, 103, 162906. [CrossRef]

4. Du, B.X.; Li, X.L.; Jiang, J.P. Surface charge accumulation and decay on directfluorinated oil-impregnated paper. IEEE Trans. Dielectr. Electr. Insul. 2016, 23, 3094-3101. [CrossRef]

5. Tang, C.; Chen, G.; Fu, M.; Liao, R. Space charge behavior in multi-layer oil-paper insulation under different DC voltages and temperatures. IEEE Trans. Dielectr. Electr. Insul. 2010, 17, 775-784. [CrossRef]

6. Hao, J.; Chen, G.; Liao, R.; Yang, L.; Tang, C. Influence of Moisture on Space Charge Dynamics in Multilayer Oil-Paper Insulation. IEEE Trans. Dielectr. Electr. Insul. 2012, 19, 1456-1464. [CrossRef]

7. Kai, W.; Zhu, Q.; Wang, H.; Xia, W.; Li, S. Space charge behavior in the sample with two layers of oil-immersed-paper and oil. IEEE Trans. Dielectr. Electr. Insul. 2014, 21, 1857-1865.

8. Wang, S.Q.; Zhang, G.J.; Mu, H.B.; Wang, D.; Lei, M.; Suwarno, S.; Tanaka, Y.; Takada, T. Effects of paper-aged state on space charge characteristics in oil-impregnated paper insulation. IEEE Trans. Dielectr. Electr. Insul. 2013, 19, 1871-1878. [CrossRef]

9. Meng, H.; Zhou, Y.; Chen, W.; Sha, Y.; Jin, F. Influence of Voltage Reversal on Space Charge Behavior in Oil-paper Insulation. IEEE Trans. Dielectr. Electr. Insul. 2014, 21, 331-339. 
10. Du, B.X.; Jiang, J.P.; Zhang, J.G.; Liu, D.S. Dynamic behavior of surface charge on double-layer oil-paper insulation under pulse voltage. IEEE Trans. Dielectr. Electr. Insul. 2016, 23, 2712-2719. [CrossRef]

11. Sun, P.; Sima, W.; Chen, J.; Zhang, D.; Jiang, X.; Chen, Q. An application area of C 60: Overall improvement of insulating oil's electrical performance. Appl. Phys. Lett. 2018, 112, 142902. [CrossRef]

12. Du, B.; Jian, L.; Wang, F.; Wei, Y.; Yao, S. Influence of Monodisperse $\mathrm{Fe}_{3} \mathrm{O}_{4}$ Nanoparticle Size on Electrical Properties of Vegetable Oil-Based Nanofluids. J. Nanomater. 2015, 2015, 3. [CrossRef]

13. Wei, Y.; Huang, Z.; Jian, L.; Wu, L.; Xiang, C. Enhanced Electrical Insulation and Heat Transfer Performance of Vegetable Oil Based Nanofluids. J. Nanomater. 2018, 2018, 4504208.

14. Abd-Elhady, A.M.; Ibrahim, M.E.; Taha, T.A.; Izzularab, M.A. Dielectric and Thermal Properties of Transformer Oil Modified by Semiconductive CdS Quantum Dots. J. Electron. Mater. 2016, 45, 1-7. [CrossRef]

15. Amiri, A.; Shanbedi, M.; Ahmadi, G.; Rozali, S. Transformer oils-based graphene quantum dots nanofluid as a new generation of highly conductive and stable coolant. Int. Commun. Heat Mass Transf. 2017, 83, 40-47. [CrossRef]

16. Song, Z.; Chao, T.; Jian, H.; Wang, X. Thermal stability and dielectric properties of nano-SiO ${ }_{2}$ doped cellulose. Appl. Phys. Lett. 2017, 111, 012902.

17. Jian, H.; Li, Y.; Liao, R.; Liu, G.; Qiang, L.; Chao, T. Fabrication of Al2O3 Nano-Structure Functional Film on a Cellulose Insulation Polymer Surface and Its Space Charge Suppression Effect. Polymers 2017, 9, 502.

18. Sahin, H.T.; Manolache, S.; Young, R.A.; Denes, F. Surface fluorination of paper in $\mathrm{CF}_{4}-\mathrm{RF}$ plasma environments. Cellulose 2002, 9, 171-181. [CrossRef]

19. Vaswani, S.; Koskinen, J.; Hess, D.W. Surface modification of paper and cellulose by plasma-assisted deposition of fluorocarbon films. Surf. Coat. Technol. 2005, 195, 121-129. [CrossRef]

20. Tan, I.H.; Silva, M.L.P.D.; Demarquette, N.R. Paper surface modification by plasma deposition of double layers of organic silicon compounds. J. Mater. Chem. 2001, 11, 1019-1025. [CrossRef]

21. An, Z.; Qiang, Y.; Chen, X.; Yue, J.; Zheng, F.; Zhang, Y. Suppression effect of surface fluorination on charge injection into linear low density polyethylene. J. Appl. Phys. 2009, 105, 13-69. [CrossRef]

22. An, Z.; Yao, J.; Mao, M.; Zhang, Y.; Xia, Z. Significantly improved charge stability of cellular polypropylene films by fluorination and subsequent annealing. J. Electrost. 2010, 68, 523-527. [CrossRef]

23. Du, B.X.; Jie, L.; Du, H.; Yi, Y. Effect of surface fluorination on space charge behavior in multilayered polyimide films. IEEE Trans. Dielectr. Electr. Insul. 2014, 21, 1817-1823. [CrossRef]

24. Zhang, B.; Zhang, G.; Qiang, W.; Li, C.; He, J.; An, Z. Suppression of surface charge accumulation on Al2O3-filled epoxy resin insulator under dc voltage by direct fluorination. Aip Adv. 2015, 5, 77-241. [CrossRef]

25. Du, B.X.; Zhu, W.B.; Li, X.L. Effects of direct fluorination on charge coupling behavior of oil-paper insulation under DC and pulse voltages. IEEE Trans. Dielectr. Electr. Insul. 2017, 24, 947-955. [CrossRef]

26. Maeno, T.; Futami, T.; Kushibe, H.; Takada, T.; Cooke, C.M. Measurement of spatial charge distribution in thick dielectrics using the pulsed electroacoustic method. IEEE Trans. Electr. Insul. 1988, 23, 433-439. [CrossRef]

27. Wang, H.H.; Lin, M.F. Modification of nylon-6 with wholly rigid poly(m-phenylene isophthalamide). J. Appl. Polym. Sci. 1991, 43, 259-269. [CrossRef]

28. Li, J.; Zhou, F.; Min, D.; Li, S.; Rong, X. The Energy Distribution of Trapped Charges in Polymers Based on Isothermal Surface Potential Decay Model. IEEE Trans. Dielectr. Electr. Insul. 2015, 22, 1723-1732. [CrossRef]

29. Wang, W.; Min, D.; Li, S. Understanding the Conduction and Breakdown Properties of Polyethylene Nanodielectrics: Effect of deep traps. IEEE Trans. Dielectr. Electr. Insul. 2015, 23, 564-572. [CrossRef]

30. Meunier, M.; Quirke, N.; Aslanides, A. Molecular modeling of electron traps in polymer insulators: Chemical defects and impurities. J. Chem. Phys. 2001, 115, 2876-2881. [CrossRef]

31. An, Z.; Chen, X.; Yue, J.; Zheng, F.; Zhang, Y. Significant suppression of space charge injection into linear low density polyethylene by surface oxyfluorination. J. Appl. Phys. 2009, 106, 11. [CrossRef]

(C) 2019 by the authors. Licensee MDPI, Basel, Switzerland. This article is an open access article distributed under the terms and conditions of the Creative Commons Attribution (CC BY) license (http://creativecommons.org/licenses/by/4.0/). 